\title{
Letter. New Google Scholar section with information on funded publications
}

\author{
Bakthavachalam Elango; Lutz Bornmann
}

How to cite this letter:

Elango, Bakthavachalam; Bornmann, Lutz (2021). "Letter. New Google Scholar section with information on funded publications". Profesional de la información, v. 30, n. 3, e300314.

https://doi.org/10.3145/epi.2021.may.14

Manuscript received on $19^{\text {th }}$ May 2021

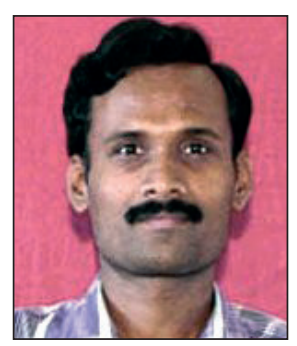

Bakthavachalam Elango $ه$ https://orcid.org/0000-0002-8938-0155

IFET College of Engineering, Library

Villupuram 605108

Tamil Nadu, India

elangokb@yahoo.com

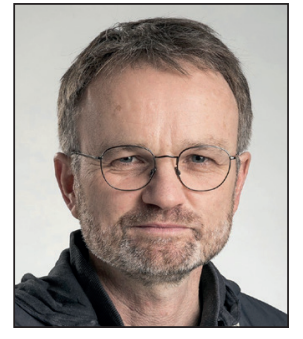

Lutz Bornmann

https://orcid.org/0000-0003-0810-7091

Science Policy and Strategy Department, Administrative Headquarters of the Max Planck Society

Hofgartenstr. 8

80539 Munich, Germany

lutz.bornmann@gv.mpg.de

\begin{abstract}
Recently, Google Scholar added a new section to the Google Scholar Author Profiles called "Public Access", with information on funded (and unfunded) publications. This Letter to the editor discusses the advantages and disadvantages of the new section.
\end{abstract}

\section{Keywords}

Bibliometrics; Funding Information; Google Scholar; Researchers; Google Scholar profile; Research Evaluation.

\section{Funding}

Not applicable

Conflict of interest

The authors declare that there are no conflicts of interest.

\section{Introduction}

Google Scholar Citations was introduced as a free online platform in 2012. The platform is viewed as an alternative to bibliographic databases such as Web of Science and Scopus (Davis, 2012). These databases are widely used for profiling authors with scholarly output and citation impact (Gasparyan et al., 2017). Authors may use Google Scholar profiles to highlight their scholarly output in a simple manner and to easily check the citing papers, graph citations over time, and compute several citation metrics. Authors can make their profiles publicly available, which means that the profiles show up in Google Scholar results when other people look up their names.

https://scholar.google.co.in/intl/en/scholar/citations.html

Today, Google Scholar is a popular tool that faculty researchers, administrators, and external reviewers use to evaluate the scholarly impact of candidates for a number of different reasons, such as jobs, tenure, and promotion (Jensenius et al., 2018). The tool can also be used for a group of authors (Thoma; Chan, 2019).

\section{Section on funding}

Very recently, Google added a new section to Google Scholar author profiles called "Public access", as shown in Figure 1 (Van-Noorden, 2021). It includes the papers that are designed to be made publicly accessible by funding agency mandates. The applicable mandates for each paper can be viewed, as well as whether the paper is not publicly accessible. A link named [PDF] or [HTML] appears if the paper has a publicly accessible version (see Figure 2). Google Scholar usually extracts the funding information from the acknowledgement sections of papers. Google Scholar automatically identifies when funding agencies are acknowledged as supporting a research with around 2,000 wording variations in a publication's text, such as "funded by" or "supported by" (Van-Noorden, 2021). 


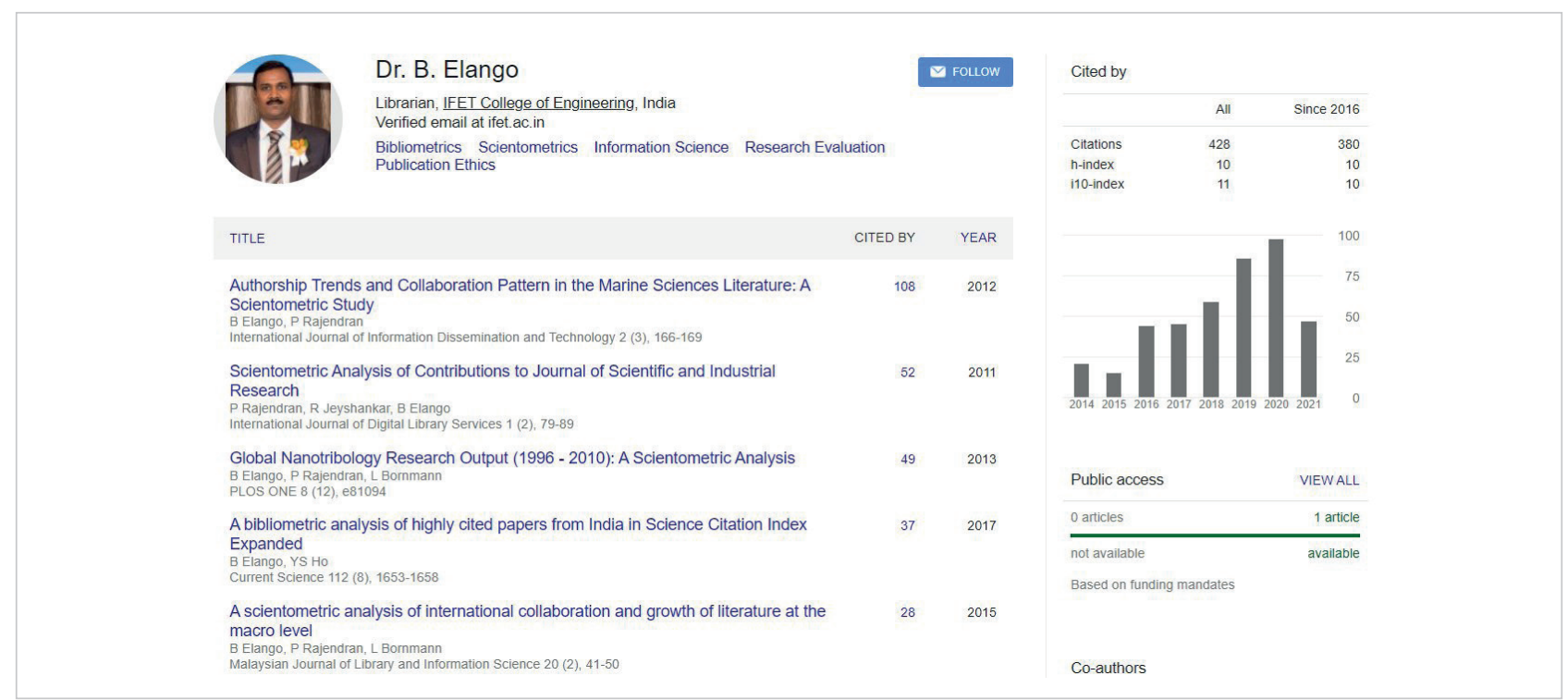

Figure 1. Google Scholar profile describing funded publications

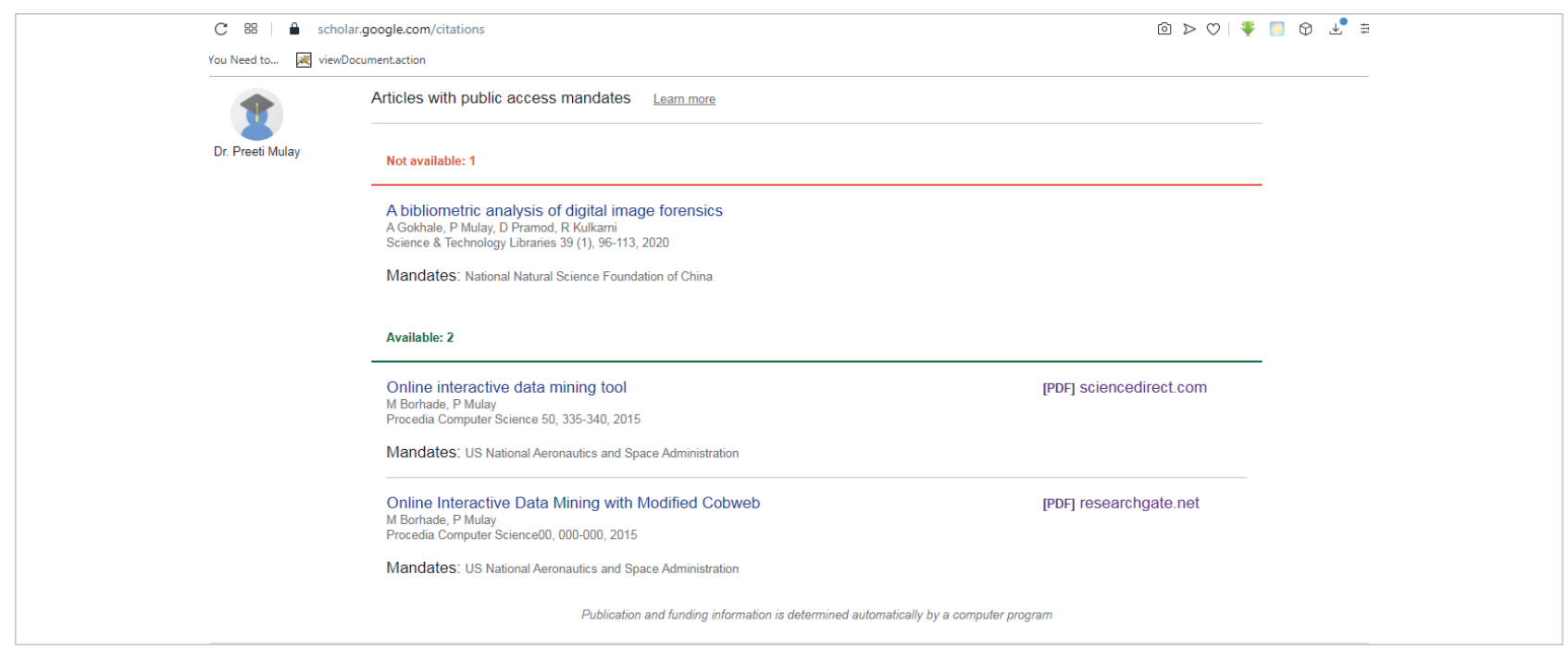

Figure 2. Link to mandated publications

There is an option for authors of certain publications to make a correction to the funding information. This involves three steps, from the review (see Figure 3) to making the corrections (see Figures 4 and 5).

\author{
Redefining Search Terms for Cybersecurity: A Bibliometric Perspective \\ B Elango, S Matilda, J Jeyasankari \\ Available at SSRN 3688394, 2020
}

Mandates: Department of Science \& Technology, India $\quad \underline{\text { REVIEW }}$

Figure 3. Step 1 of funding agency correction

\title{
Redefining Search Terms for Cybersecurity: A Bibliometric Perspective
}

B Elango, S Matilda, J Jeyasankari

Available at SSRN 3688394, 2020

- Department of Science \& Technology, India cached

Effective date: 2012/4 Embargo: 6 months

Funding acknowledgment in paper: ....Department of Science and Technology (DST), Government of India for financial support vide Reference No. DST/NSTMIS/05/236/2017-18 ..

\section{UPLOAD PDF MAKEA CORRECTION}




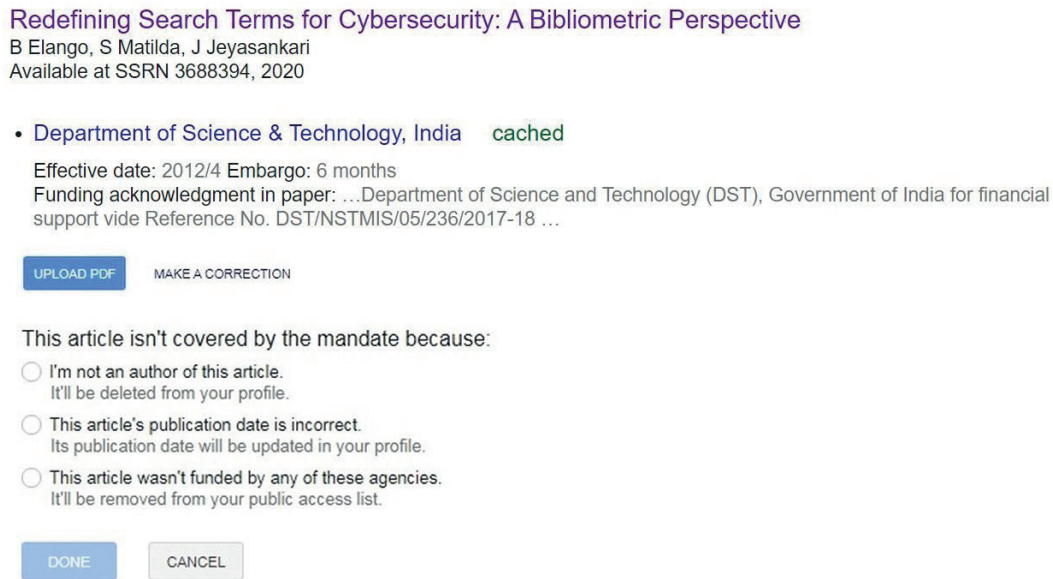

Figure 5. Step 3 of funding agency correction

In Google Scholar, the term "research funding" refers to any funding for scientific research in any field. Basically, there are two sources of funding:

(i) governments with various funding agencies such as the Indian Department of Science and Technology and the US National Science Foundation, and

(ii) non-government organizations with research and development departments such as the Tata Group or Microsoft. For many years now, there has been a broad debate around the fact that when public means are used to fund science, the results should be made publicly available (without any restrictions). For example, according to the Agency for Healthcare Research \& Quality (AHRQ), scientists are expected to deposit their publications (from the funded research) in the PubMed Central database. A "mandate" (in case of research) is a regulation that mandates or recommends researchers (university faculty researchers, research staff or research grant recipients) to make their publications (peer reviewed journal articles and conference papers) open access.

There are different mandates for different funding agencies and institutions. The term "embargo period" indicates the time when a paper must be made available for open access after publication/completion. This period varies for different organizations. For example, it is twelve months for the US National Institutes of Health and six months for the Indian Department of Science and Technology.

In our opinion, the new service by Google Scholar is very informative and useful due to the fact that it identifies funded and non-funded publications. For example, three funded publications have been identified by Google Scholar and displayed for an author (see Figure 2) and it is found that all the three publications were not funded by any funding agency (Gokhale et al., 2020; Borhade; Mulay, 2015). However, we found some inconsistencies with the new service that should be considered when using it:

\section{(1) Identification of funding agencies for non-funded papers}

Google Scholar identifies funding agencies that do not exist. For example, Google Scholar indicates a specific funding agency for Bornmann, Wallon \& Ledin (2008), although the authors clearly state that there was no support or funding.

\section{(2) Mistaken indication of funding agencies}

Google Scholars' algorithm mistakes funding agencies (see Table 1). For example, the "Health Research Council of New Zealand" is the correct funding agency for Theadom et al. (2016); Google Scholar identified the "Swedish Research Council".

Google Scholar identified "UK Research \& Innovation" as a funding agency for Baggott et al. (2020), which is in contrast to "Research for Life" mentioned in the paper.

In the same way, Google Scholar identified the "Government of Spain, Autism Speaks Inc, USA, US National Institutes of Health" as funding agencies for Lee et al. (2012), instead of the "National Institute of Neurological Disorders and Stroke" (Ninds), and the "CHDI Foundation". 
Table 1. Mistaken indication of funding agencies

\begin{tabular}{|c|c|c|}
\hline Funding agency identified by Google Schola & & Funding information given in the paper \\
\hline $\begin{array}{l}\text { Exploring the experience of sleep and fatigue in male and female adults over the } 2 \\
\text { years following traumatic brain injury: a qualitative descriptive study } \\
\text { A Theado, V Rowand, W Levack, N Starkey, L Wikinson-Meyers,... } \\
\text { BMJ open } 6 \text { (4), e010453, 2016 } \\
\text { Mandates: Swedish Research Council }\end{array}$ & [HTML] bmj.com & $\begin{array}{l}\text { The parent study informing this work was supported by } \\
\text { the Health Research Council of New Zealand, grant number } \\
\text { 10/471. }\end{array}$ \\
\hline $\begin{array}{l}\text { Patient preferences for asthma management: a qualitative study } \\
\text { C Baggott, A Chan, S Hurford, J Fingleton, R Beasley, M Harwood, ... } \\
\text { BMJ open } 10 \text { (8), e037491, } 2020 \\
\text { Mandates: UK Research \& Innovation }\end{array}$ & [PDF] bmj.com & $\begin{array}{l}\text { The study was funded by a grant from Research for Life } \\
\text { (2019/300) and the study sponsor was the Medical Re- } \\
\text { search Institute of New Zealand (MRINZ). The MRINZ receives } \\
\text { independent research organisation funding from the Heal- } \\
\text { th Research Council of New Zealand. }\end{array}$ \\
\hline $\begin{array}{l}\text { CAG repeat expansion in Huntington disease determines age at onset in a fully } \\
\text { dominant fashion } \\
\text { JM Lee, EM Ramos, JH Lee, T Gillis, JS Mysore, MR Hayden, SC Warby, ... } \\
\text { Neurology } 78 \text { (10), } 690-695,2012 \\
\text { Mandates: Govermment of Spain, Autism Speaks Inc, USA, US National Institutes of Health }\end{array}$ & [HTML] nih.gov & $\begin{array}{l}\text { Supported by grants from the National Institute of Neuro- } \\
\text { logical Disorders and Stroke (Ninds) ("Huntington's Disease } \\
\text { Center Without Walls"; NS016367), the CHDI Foundation, } \\
\text { Inc., and the Huntington's Disease Society of America's Coa- } \\
\text { lition for the Cure. }\end{array}$ \\
\hline
\end{tabular}

\section{(3) Identification of the funding agency from an author biography}

In some cases, Google Scholar appears to identify the funding agency from an author biography. For example, an author provided his biography in Ali and Khan (2017), which includes the following:

"Earlier, he successfully completed 4 research projects funded by the Department of Science and Technology

(DST) and the Indian Council of Social Science Research (ICSSR), and two by the University Grants Commission."

Google Scholar erroneously identifies the funding agency for the paper (see Figure 6) as being the Department of Science \& Technology, India.

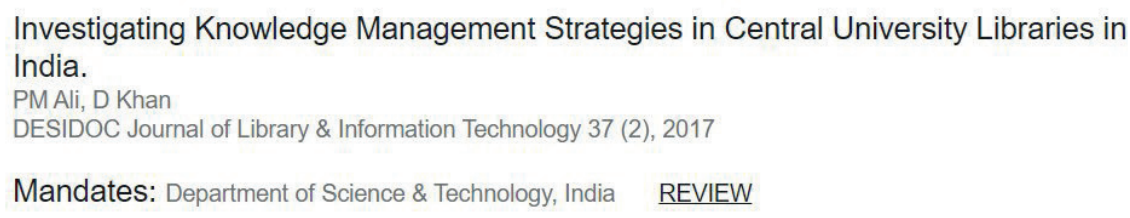

Figure 6. Identification of the funding agency from an author biography

\section{(4) Identification of funding agencies from authors' affiliations}

In some cases, Google Scholar seems to identify the funding agency from authors' affiliations. For example, in Thelwall et al. (2015), the following statement is provided which clearly indicates that some authors are employed at the Wellcome Trust.

"Though no specific funding was awarded in support of this paper, KD and AD are employed by the Wellcome Trust."

Google Scholar identified the funding agency for the paper (see Figure 7) as the Welcome Trust.

$$
\begin{aligned}
& \text { Alternative metric indicators for funding scheme evaluations } \\
& \text { M Thelwall, K Kousha, A Dinsmore, K Dolby } \\
& \text { Aslib Journal of Information Management, } 2015 \\
& \text { Mandates: Wellcome Trust REVIEW }
\end{aligned}
$$

Figure 7. Identification of funding agencies from author affiliations

\section{(5) Identification of funding agencies from acknowledgement sections for providing general help}

In some cases, Google Scholar appears to identify the funding agency from acknowledgement sections for providing general help. For example, Sharma et al. (2018) acknowledged two institutions for providing the data for a study, as shown in Figure 8.

Acknowledgement. The authors are thankful to NRSC, India and USGS, USA for providing the satellite data used in the present study. 
However, Google Scholar identifies the US Geological Survey as being the funding agency (see Figure 9).

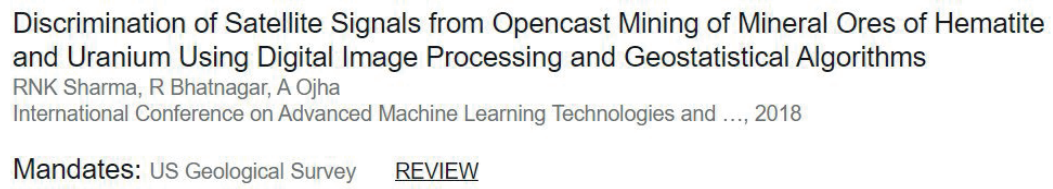

Figure 9. Identification of funding agencies from acknowledgement sections for providing general help sections for providing general help

(6) Google Scholar identifies funding agencies from acknowledgement sections although the paper has two sections: funding information and acknowledgements

In some cases, Google Scholar appears to identify the funding agency from acknowledgement sections, although the paper has two sections: funding information and acknowledgements. For example, Pereira et al. (2017) has two sections: funding information and acknowledgement (see Figure 10). Google Scholar erroneously identifies funding information in the acknowledgement section, although the information is in the funding information section.

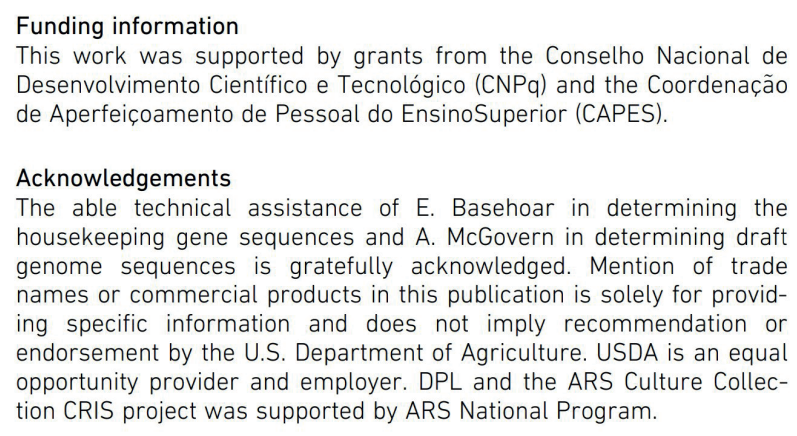

Figure 10. Google Scholar identifies funding agencies from the acknowledgement section although the paper has two sections, funding information and acknowledgements

\section{(7) Identification of funding agencies from the body of a paper}

In some cases, Google Scholar appears to identify the funding agency from the body of a paper. For example, Pathak et al. (2017) was not supported by any agency. However, from the body of the paper, Google Scholar identifies the funding agency as being the Department of Science and Technology. The agency was mentioned in a table (see Figure 11).

\begin{tabular}{|c|c|c|c|}
\hline \multicolumn{4}{|c|}{$\begin{array}{c}\text { Table-9 } \\
\text { Funding Agencies }\end{array}$} \\
\hline Sl. No. & $\begin{array}{c}\text { Funding Agencies } \\
\end{array}$ & Articles & Percentage \\
\hline 1 & Department of Science and Technology (DST) & 280 & 33.7 \\
\hline 2 & University Grants Commission & 209 & 25.2 \\
\hline 3 & Department Of Biotechnology (DBT) & 96 & 11.6 \\
\hline 4 & Council of Scientific and Industrial Research (CSIR) & 61 & 7.3 \\
\hline 5 & Worldwide LHC Computing Grid (WLCG) & 50 & 6.0 \\
\hline 6 & Grid Centres; Worldwide LHC Computing Grid (WLCG) & 45 & 5.4 \\
\hline 7 & $\begin{array}{l}\text { State Committee of Science; World Federation of Scientists } \\
\text { (WFS) }\end{array}$ & 30 & 3.6 \\
\hline 8 & Science and Engineering Research Board & 29 & 3.5 \\
\hline 9 & Indian Council of Medical Research & 19 & 2.3 \\
\hline 10 & $\begin{array}{l}\text { A.I. Alikhanyan National Science Laboratory (Yerevan } \\
\text { Physics Institute) Foundation (ANSL) }\end{array}$ & 11 & 1.3 \\
\hline & Total- & 830 & 100.0 \\
\hline
\end{tabular}

Figure 11. Identification of funding agencies from the body of a paper.

Source: Pathak, Mishra \& Verma (2017).

\section{(8) Identification of single funding agencies for multiple agencies mentioned in a paper}

In some cases, Google Scholar appears to identify single funding agencies for multiple agencies mentioned in a paper. For example, Dharmani et al. (2009) has acknowledged more than one funding agency that has supported their research:

Research in Dr. Chadee's laboratory is supported by grants from the Canadian Institutes for Health Research, the Crohn's and Colitis Foundation of Canada, the Canadian Foundation for Innovation, the Natural Sciences and Engineering Research Council of Canada and the Canadian Association of Gastroenterology-Astra Zeneca-CIHR Research and Fellowship Awards. Dr. Chadee holds a Tier 1 Canada Research Chair in gastrointestinal inflammation. 
However, Google Scholar identifies the funding agency (see Figure 12) for the paper as being the Canadian Institutes of Health Research only.

Role of intestinal mucins in innate host defense mechanisms against pathogens

P Dharmani, V Srivastava, V Kissoon-Singh, K Chadee

Journal of innate immunity 1 (2), 123-135, 2009

Mandates: Canadian Institutes of Health Research $\quad \underline{\text { REVIEW }}$

Figure 12. Identification of single funding agencies for multiple agencies that supported the research

\section{Conclusion}

Since our unsystematic use of the new Google Scholar service revealed many erroneous entries, we strongly suggest that the identification of research funding from papers should be significantly improved. When using the service, we noticed that Google Scholar appears to be in the process of improving the identification of funding information. Only with optimized data can the provided information/service be used for research evaluation purposes.

\section{References}

Ali, P. M. Naushad; Khan, Daud (2017). “Investigating knowledge management strategies in Central University Libraries in India". Desidoc journal of library \& information technology, v. 37, n. 2, pp. 73-78.

https://bit.ly/3i8MoCj

Baggott, Christina; Chan, Amy; Hurford, Sally; Fingleton, James; Beasley, Richard; Harwood, Matire; Reddel, Helen K.; Magnus-Levack, William-Mark (2020). "Patient preferences for asthma management: a qualitative study". BMJ open, v. 10, n. 8, e037491.

https://doi.org/10.1136/bmjopen-2020-037491

Borhade, Mahesh; Mulay, Preety (2015). “Online interactive data mining tool”. Procedia computer science, v. 50, pp. 335-340.

https://doi.org/10.1016/j.procs.2015.04.039

Bornmann, Lutz; Wallon, Gerlind; Ledin, Anna (2008). "Does the committee peer review select the best applicants for funding? An investigation of the selection process for two European molecular biology organization programmes". PLoS one, v. 3, n. 10.

https://doi.org/10.1371/journal.pone.0003480

Davis, Phil (2012). Gaming Google Scholar citations, made simple and easy.

https://scholarlykitchen.sspnet.org/2012/12/12/gaming-google-scholar-citations-made-simple-and-easy

Dharmani, Poonan; Srivastava, Vikas; Kissoon-Singh, Vanessa; Chadee, Kris (2009). "Role of intestinal mucins in innate host defense mechanisms against pathogens". Journal of innate immunity, v. 1, n. 2, pp. 123-135.

https://doi.org/10.1159/000163037

Gasparyan, Armen-Yuri; Nurmashev, Bekaidar; Yessirkepov, Marlen; Endovitskiy, Dmitry A.; Voronov, Alexander A.; Kitas, George D. (2017). "Researcher and author profiles: opportunities, advantages, and limitations". Journal of Korean medical science, v. 32, n. 11, pp. 1749-1756.

https://doi.org/10.3346/jkms.2017.32.11.1749

Gokhale, Angelina; Mulay, Preeti; Pramod, Dhanya; Kulkarni, Ravi (2020). “A bibliometric analysis of digital image forensics". Science \& technology libraries, v. 39, n. 1, pp. 96-113.

https://doi.org/10.1080/0194262X.2020.1714529

Jensenius, Francesca R.; Htun, Mala; Samuels, David J.; Singer, David A.; Lawrence, Adria; Chwe, Michael (2018). "Benefits and pitfalls of Google Scholar". PS: Political science and politics, v. 51, n. 4, pp. 820-824.

https://doi.org/10.1017/S104909651800094X

Lee, J. M.; Ramos, E. M.; Lee, J. H.; Gillis, T.; Mysore, J. S.; Hayden, M. R.; Warby, S. C.; Morrison, P.; Nance, M.; Ross, C. A.; Margolis, R. L.; Squitieri, F. et al. (2012). "CAG repeat expansion in Huntington disease determines age at onset in a fully dominant fashion". Neurology, v. 78, n. 10, pp. 690-695.

https://doi.org/10.1212/wnl.0b013e318249f683

Pathak, Triveni; Mishra, Virendra-Kumar; Verma, Manoj-Kumar (2017). "Research publication analysis of faculty members of Gauhati University during 1989-2018: A bibliometric study". International journal of library information network, v. 5, n. 1, pp. 73-91.

https://www.academia.edu/44089561/Research_Publication_Analysis_of_Faculty_Members_of_Gauhati_University_ during_1989_2018_A_Bibliometric_Study 
Pereira, Pedro-Henrique-Freitas; Macrae, Andrew; Reinert, Fernanda; De-Souza, Rodrigo-Fonseca; Coelho, Rosalie-Reed-Rodrigues; Pötter, Gabrielle; Klenk, Hans-Peter; Labeda, David P. (2017). "Streptomyces odonnellii sp. nov., a proteolytic streptomycete isolated from soil under cerrado (savanna) vegetation cover". International journal of systematic and evolutionary microbiology, v. 67, n. 12, pp. 5211-5215.

https://doi.org/10.1099/ijsem.0.002446

Sharma, Richa N. K.; Bhatnagar, Roheet; Ojha, Abhishekh (2018). "Discrimination of satellite signals from opencast mining of mineral ores of hematite and uranium using digital image processing and geostatistical algorithms". In: International conference on advanced machine learning technologies and applications (pp. 193-199). Cham: Springer.

https://link.springer.com/book/10.1007/978-3-319-74690-6

Theadom, Alice; Rowland, Vickie; Levack, William; Starkey, Nicola; Wilkinson-Meyers, Laura; McPherson, Kathryn (2016). "Exploring the experience of sleep and fatigue in male and female adults over the 2 years following traumatic brain injury: a qualitative descriptive study". BMJ open, v. 6, n. 4, e010453.

https://doi.org/10.1136/bmjopen-2015-010453

Thelwall, Mike; Kousha, Kayvan; Dinsmore, Adam; Dolby, Kevin (2015). "Alternative metric indicators for funding scheme evaluations". Aslib journal of information management, v. 68, n. 1, pp. 2-18.

https://doi.org/10.1108/AJIM-09-2015-0146

Thoma, Brent; Chan, Teresa M. (2019). "Using Google Scholar to track the scholarly output of research groups". Perspectives on medical education, v. 8, n. 3, pp. 201-205.

https://doi.org/10.1007/s40037-019-0515-4

Van-Noorden, Richard (2021). “Do you obey public-access mandates? Google Scholar is watching”. Nature (in Press). https://doi.org/10.1038/d41586-021-00873-8

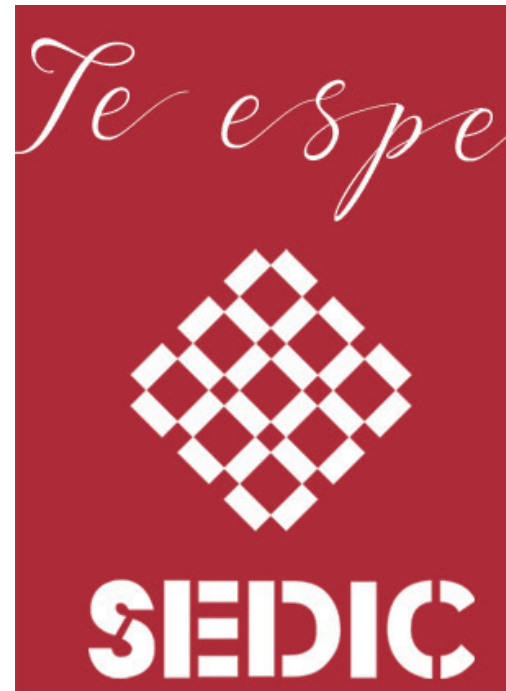

ramos ew www.sedic.es

c/Rodríguez San Pedro 2, oficina 606. 28015 Madrid

Tfno: +34915934059

secretaria@sedic.es

Sociedad

Española de Documentación e Información

\section{Científica}

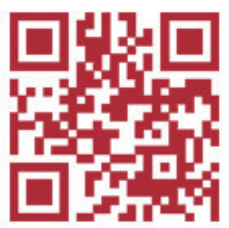

https://twitter.com/SEDIC20

f https://wwww.facebook.com/AsociacionSEDIC

in https://www.linkedin.com/groups?home=\&gid=5060038 